\title{
Isolation of Aerobic Bacteria from Surgical Site Infection and their Antibiotic Susceptibility Pattern
}

\author{
Shahin Ara Begum ${ }^{1}$, Shabeen Afreen ${ }^{2}$, Aliya Rashid ${ }^{3}$, Nasreen Farhana ${ }^{4}$
}

\begin{abstract}
${ }^{1}$ Associate Professor, Department of Microbiology, Dhaka Medical College, Dhaka, Bangladesh; ${ }^{2}$ Junior Consultant, Department of Gynaecology \& Obstetrics, Kurmitola General Hospital, Dhaka, Bangladesh; ${ }^{3}$ Associate Professor, Department of Microbiology, Shaheed Suhrawardy Medical college, Dhaka, Bangladesh; ${ }^{4}$ Clinical Pathologist, Department of Microbiology, Dhaka Medical College, Dhaka, Bangladesh
\end{abstract}

[Received: 1 January 2015; Accepted: 15 March 2015; Published: 1 June 2015]

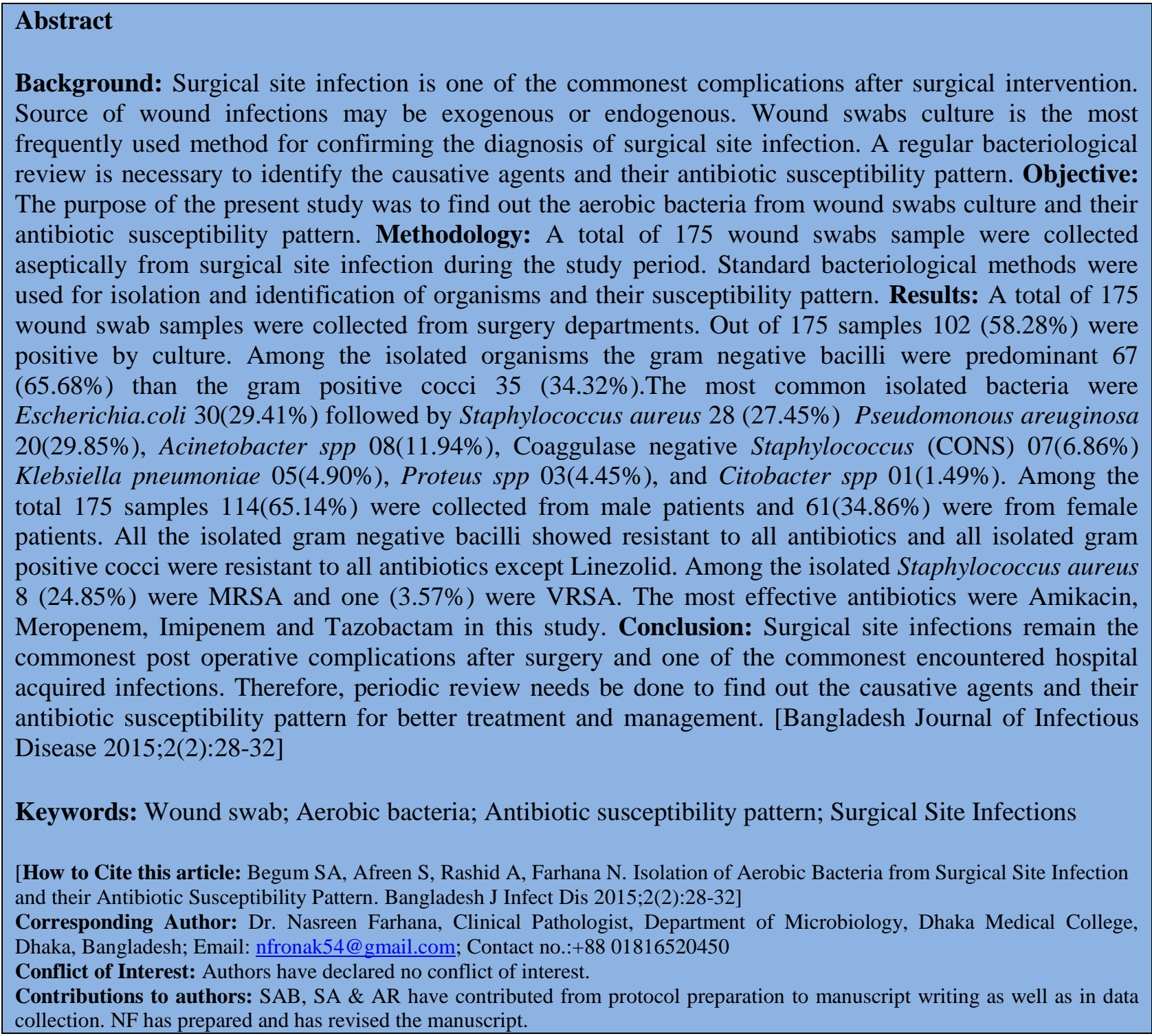




\section{Introduction}

Surgical site infections are global problem in the field of surgery associated with long hospital stay, higher treatment expenditure and increase the morbidity and mortality rate ${ }^{1}$. Surgical site infections (SSIs) are defined as an infection that occurs within 30 days after surgery ${ }^{2}$. SSIs are the second most commonly encounter type of nosocomial infection in United States ${ }^{3}$. The centers for diseases control and prevention (CDC) that SSIs are associated with a mortality rate $3.0 \%{ }^{4}$. Surgical site infection risk depends upon a number of patients factors including pre existing medical conditions, amount and type of resistant skin bacteria, preoperative, intra operative and post-operative care 5 .

Wound infections are caused by deposition and multiplication of microorganisms in the surgical site of a susceptible host. In fact most infection of post operative wound are hospital acquired and varies from one hospital to others ${ }^{6-8}$. Lack of standardized criteria for diagnosis of SSIs present a challenge to monitor the global epidemiology of surgical site infection ${ }^{1}$. In addition to this, emerging of high antimicrobial resistance among bacterial pathogens has made the management and treatment of post-operative wound infection difficult $^{6}$. Moreover, rapidly emerging nosocomial pathogens and the problem of multidrug resistance necessitates periodic review of isolation pattern and their sensitivity ${ }^{9}$. Many studies in different part of the world found that the most frequently isolated bacteria from surgical wound infections were Staphylococcus aureus, coagulase negative Staphylococcus (CoNS), Escherichia coli, Pseudomonas aeruginosa, Klebsiella pneumoniae, Proteus species ${ }^{10-11}$.

Study in India and Bangladesh showed that the most frequently isolated bacteria were Escherishia coli, Staphylococcus aureus, Klebsiella pneumoniae, Pseudomonas aeruginosa, Proteus species, Acinetobacter species and Citrobacter species $^{12-13}$. This study was carried out to determine and distribution of common aerobic bacteria and their antimicrobial susceptibility patterns in patients with clinical diagnosis of post operative wound infection.

\section{Methodology}

This cross sectional study was conducted in a private hospital in Dhaka City named Green Life Hospital from January 2014 to May 2015 for a period of one and half year. Green Life Hospital is a private hospital in Dhaka city which has 300 bed capacities. Samples were collected from all age group who undergo surgery and developed SSIs as diagnosed clinically by physicians within 30 days after surgery. Wound swabs were collected under all aseptic precaution and were kept in a sterile test tube and then were sent to the microbiology laboratory immediately. All the specimens were inoculated in 5\% Blood agar, Chocolate agar and MacConkey's agar media. All plates were incubated overnight aerobically at $37^{\circ} \mathrm{C}$ for 24 hours. The bacterial pathogens were identified by colony morphology, Gram staining, biochemical tests according to standard microbiological technique. Antimicrobial susceptibility was performed on Mueller-Hinton agar media by standard disc diffusion method recommended by National Committee for clinical laboratory Standard (NCCLS). The antibiotics were tested for gram positive and gram negative bacteria by Kirby Bauer method. Data analysis was carried out by using SPSS.

\section{Result}

A total of 175 wound swabs were collected under all aseptic precaution. Out of a total 175 samples, 102(58.28\%) were positive by culture.

Table 1: Sex Distribution among the Study Population $(n=175)$

\begin{tabular}{lcc}
\hline Sex & Frequency & Percentage \\
\hline Male & 114 & 65.14 \\
Female & 61 & 34.86 \\
Total & $\mathbf{1 7 5}$ & $\mathbf{1 0 0 . 0}$ \\
\hline
\end{tabular}

A total 102 strains were isolated, out of which $67(65.68 \%)$ were Gram negative bacilli and $35(34.32 \%)$ were Gram positive cocci. Among the total 175 samples $114(65.14 \%)$ were collected from male patients and 61(34.85\%) were collected from female patients (Table 1).

Table 2: Age Distribution among the Study Population $(\mathbf{n}=175)$

\begin{tabular}{lcc}
\hline Age group & Frequency & Percentage \\
\hline $0-15$ & 21 & 12.0 \\
$15-40$ & 63 & 36.0 \\
$40-60$ & 64 & 36.5 \\
$>60$ & 27 & 15.4 \\
Total & $\mathbf{1 7 5}$ & $\mathbf{1 0 0 . 0}$ \\
\hline
\end{tabular}


Overall infection rate was highest in the age range 15 to 60 years and lowest in the age range 0 to 15 years (Table 2).

Table 3: Distribution of Organism Isolated from Post-Surgical Wound Infection $(n=102)$

\begin{tabular}{lcc}
\hline Bacteria & Frequency & Percentage \\
\hline Staph. aureus & 28 & 27.4 \\
$\bullet \quad$ MRSA & 08 & \\
Stap epidermidis & 07 & 6.86 \\
Escherichia coli & 30 & 29.41 \\
P. aeroginosa & 20 & 19.60 \\
Acinetobacter spp & 08 & 7.83 \\
Kleb. pneumonia & 05 & 4.90 \\
Proteus spp & 03 & 2.93 \\
Citobacter spp & 01 & 0.97 \\
Total & $\mathbf{1 0 2}$ & $\mathbf{1 0 0 . 0}$ \\
\hline
\end{tabular}

Among the Gram negative bacilli the most common bacilli were Escherichia coli which was $30(44.77 \%)$ isolates followed by Pseudomonas aeruginosa, Acinetobacter species, Klebsiella pneumoniae, Proteus species and Citrobacter species $20(29.85 \%)$ isolates, $8(11.94 \%)$ isolates, $5(4.90 \%)$ isolates, $3(4.45 \%)$ isolates and $1(1.49 \%)$ isolates respectively. Out of 35(34.32\%) isolated Gram positive cocci the commonest were Staphylococcus aureus which was 28(80.0\%) isolates followed by coagulase negative Staphylococcus (CONS) which was 7(20\%) isolates (Table 3). Samples were collected from orthopedic surgery in $44(25.14 \%)$ cases, vascular surgery in $43(24.57 \%)$ cases, general surgery in $42(24 \%)$ cases, thoracic surgery in $23(13.14 \%)$ cases, neurosurgery in $11(6.28 \%)$ cases, Gynaecology \& Obstetrics in $5(2.85 \%)$ cases, ENT in $4(2.28 \%)$ cases and $3(1.17 \%)$ from paediatric surgery.

Table 4: Antibiotic Resistance Pattern of Gram Negative Bacteria (n=67)

\begin{tabular}{|c|c|c|c|c|c|c|}
\hline Antibiotic & 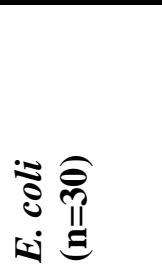 & 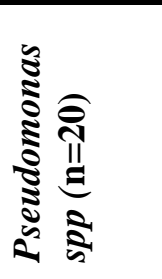 & 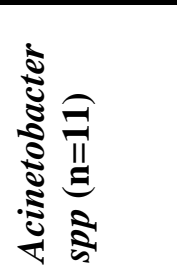 & 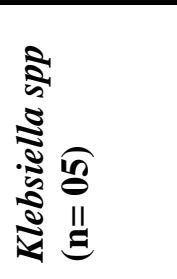 & 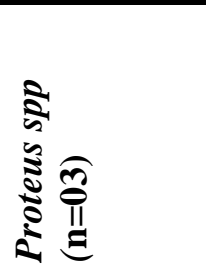 & 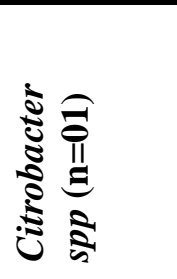 \\
\hline Amoxicillin & $10(33.4)$ & $20(100)$ & $11(100)$ & $04(90)$ & $02(66.66)$ & $01(100)$ \\
\hline Amikacin & $04(13.8)$ & $09(49)$ & $10(90)$ & $02(40)$ & $02(66.66)$ & $0(0)$ \\
\hline Ceftazidime & $08(26.7)$ & $12(60)$ & 11(100) & $05(100)$ & $03(100)$ & $0(0)$ \\
\hline Ceftriaxone & $18(60)$ & $18(90)$ & 11(100) & $05(100)$ & 03(100) & $0(0)$ \\
\hline Cefuroxime & $20(66.7)$ & $18(90)$ & 11(100) & $04(90)$ & $03(100)$ & $1(100)$ \\
\hline Ciprofloxacin & $18(60)$ & $15(75)$ & 11(100) & $04(90)$ & $03(100)$ & $0(0)$ \\
\hline Gentamicin & $11(36.7)$ & $18(90)$ & $10(90)$ & $04(90)$ & $03(100)$ & $0(0)$ \\
\hline Levofloxacin & $16(53.4)$ & $05(25)$ & $10(90)$ & $02(40)$ & $03(100)$ & $0(0)$ \\
\hline Imipenem & $01(3.6)$ & $05(25)$ & $10(90)$ & $0(0)$ & $01(33.33)$ & $0(0)$ \\
\hline Meropenem & 01(3.6) & $05(25)$ & $10(90)$ & $0(0)$ & $01(33.33)$ & $0(0)$ \\
\hline Piperpicilin & $04(13.4)$ & $04(20)$ & 11(100) & 04(90) & $02(66.66)$ & $0(0)$ \\
\hline Tazobactum & $0(0)$ & $02(10)$ & 11(100) & $01(10)$ & $0(0)$ & $0(0)$ \\
\hline
\end{tabular}

The susceptibility patterns of antibiotic of isolated bacteria are showed in the Table $4 \& 5$.

\section{Discussion}

Surgical site infection is the most commonly and frequently reported nosocomial infections in the world $^{14}$. SSIs rate has varied from as low of $2.5 \%$ to a high of $41.9 \%{ }^{15}$. In spite of the progress in the field of surgery, surgical technique and antibiotic prophylaxis, post-operative wound infection remain the commonest post-operative complications and one of the frequently encountered hospital acquired infection in the world wide ${ }^{8}$. This study gives an insight to the causative pathogens of post operative wound infections and their susceptibility patterns. In this study the isolation rate was (58.28\%). Similar isolation rate $(55.4 \%)$ was reported by Sikka et $\mathrm{al}^{14}$ in India in 2015. However other studies in Ethiopia found that the isolation rate of bacteria was $71.1 \%^{17}$ and $75 \%{ }^{18}$ and in Nepal isolation rate was $80.0 \%{ }^{6}$. In this study the isolation rate was lower than the previous study that took place in Ethiopia and Nepal, probably SSIs caused 
by anaerobic bacteria or patients were under antibiotics treatment or presence of fastidious organism.

Table 5: Antibiotic Resistance Pattern of Gram Positive Bacteria $(\mathbf{n}=35)$

\begin{tabular}{lll}
\hline Antibiotic & $\begin{array}{l}\text { Sta. aureus } \\
(\mathbf{n = 2 8})\end{array}$ & $\begin{array}{l}\text { CONS } \\
(\mathbf{n}=\mathbf{0 7})\end{array}$ \\
\hline Augmentin & $12(42.85)$ & $03(42.85)$ \\
Amikacin & $12(42.85)$ & $02(28.57)$ \\
Cefuroxime & $25(89.28)$ & $02(28.57)$ \\
Ceftriaxone & $13(46.42)$ & $01(14.28)$ \\
Ceftazidime & $17(60.71)$ & $01(14.28)$ \\
Ciprofloxacin & $22(78.57)$ & $01(14.28)$ \\
Co-trimoxazole & $12(42.85)$ & $01(14.28)$ \\
Clindamycin & $26(92.85)$ & $06(85.71)$ \\
Gentamicin & $17(60.71)$ & $03(42.85)$ \\
Levofloxacin & $18(64.28)$ & $2(28.57)$ \\
Meropenem & $12(42.85)$ & $2(28.57)$ \\
Imepenem & $14(50)$ & $03(42.85)$ \\
Oxacillin & $8(24.85)$ & $01(14.28)$ \\
Doxacycillin & $10(35.71)$ & $02(28.57)$ \\
Vancomycin & $01(3.57)$ & $0(0)$ \\
Linozolid & $0(0)$ & $0(0)$ \\
\hline *Augmentin= Amoxicillin/ Clavulanic acid
\end{tabular}

*Augmentin= Amoxicillin/ Clavulanic acid

In this study the isolation rate of Gram negative bacilli was higher (65.68\%) than the Gram positive cocci $(34.32 \%)$. Similar observations are also reported from Ethiopia where the Gram negative bacilli were found in $59.3 \%$ cases and Gram positive cocci in $40.7 \%$ cases $^{16}$. From India the Gram negative bacilli (62.7\%) were present predominantly than the gram positive cocci (37.3\%); furthermore, Escherichia coli was the most prevalent isolate among gram negative bacilli $^{11}$. Another study in Pakistan has been reported that the isolation rate of Gram negative bacilli was higher than the gram positive cocci and the most frequent isolates were Escherichia coli $60.7 \%$. In this study the most frequent isolates were Escherichia coli (29.7\%) followed by Staphylococcus aureus (27.4\%), Pseudomonas aeruginosa (19.6\%), Acinetobacter species (7.8\%), Klebsiella pneumoniae (4.9\%), Proteus species $(2.93 \%)$, Citrobacter species $(0.97 \%)$. However, Das et $\mathrm{al}^{7}$ found that the predominant isolated organisms were Staphylococcus aureus (24.3\%) and followed by Escherichia coli (18.9\%), Pseudomonas species (18.9\%), Enterobacter species $(8.1 \%)$ and Citrobacter species $(8.1 \%)$ and also Santos et $\mathrm{al}^{18}$ found that the Staph. aureus was the most frequent $(33.9 \%)$ followed by Esch. coli $(20.3 \%)$.
High infection rate was found in male (65.14\%) patients than in female patients $(34.86 \%)$ in this study. Similar observation also reported from Nepal that the infection rate was $(62.5 \%)$ in male patients and $(53.1 \%)$ in female patients ${ }^{5}$. The reason behind this variation has not yet been established clearly ${ }^{7}$.

In this study the isolated gram negative bacilli showed resistant all antibiotics. Among the isolated gram negative bacilli, Acinetobacter species showed higher percentage of antibiotics resistance. During the study period it was found that most efficient antibiotics were meropenem, imipenem, amikacin, pipercilli, tazobactum and linozolid and vancomycin and linozolid. Staphylococcus aureus showed $8(24.85 \%)$ MRSA and 01(3.57\%) VRSA in this study. Isolation of MRSA was $2.2 \%$ noted by Amatya et $\mathrm{al}^{5}$. Isolation of MRSA was higher (40$50.5 \%)$ noted $^{19}$ and $26(76.47 \%)$ MRSA by Diaz et $\mathrm{al}^{20}$. There were some limitations of this study. This study did not isolate strict anaerobe bacteria and fungi, which could have increased the numbers of isolates bacteria reported as negative growth.

\section{Conclusion}

It is concluded that post surgical wound infection were associated with gram negative bacilli and gram positive cocci. Results showed that high rate of antibiotics resistance to most of the isolated pathogens. A regular surveillance should be carried out to monitor the susceptibility pattern of isolated pathogens and chose appropriate regimens for the treatment of post surgical wound infection. There is need to develop an antibiotic policy and guideline to prevent or reduce indiscriminate use of antibiotic and preserve their effectiveness for treatment and management of post-surgical wound infection.

\section{References}

1. Menesha RE, Kasa GBS, Saravanan M, Berhe DF, Wasihun AG: Aerobic bacteria in post-surgical wound infections and patter of their antimicrobial susceptibility in Ayder Teaching and Referal Hospital, Mekelle, Ethiopia. BMC Res Notes 2014;7: 575

2. Nagan : Wound infection, Dermnet Newzeland trust 2014

3. Isibor JO, Oseni A, EyaufeA, Osagien R, Turay A. Incidence of aerobic bacteria and Candida albicans in post-operative wound infections. African J Microbiol Res 2008;2:288-91

4. Mulu W, Kibru G, Beyene G, Danile A. Post-operative Nosocomial infections and Antimicrobial resistances pattern of Bacteria isolates among patients Admitted at Feleg Hiwot Referral Hospital, Bahirdar, Ethopia. Ethiopian J Health Sci 2012;22(1):7-1

5. Amatya J, Rijal M, Baidya R. Bacteriological Study of the Post operative wound Samples and Antibiotic Susceptibility Pattern of the Isolates in B\&B Hospital. JSM Microbiol 2015; 3(1) :1019 
6. Raza MS, Chander A, Ranabhat A. Antimicrobial Susceptibility patterns of the Bacterial Isolates in Post Operative Wound Infection in Tertiary Care Hospital, Kathmundu Nepal. Open J Med Microbiol 2013;3(3)

7. Das R, Singh A, Srivastava P, Pradhan S, Murthy R. Microbial profile and Antibiotic Susceptibility Pattern of Surgical Site Infection in Orthopaedic Patients at a Tertiary Hospital in Bilaspur. International J Sci Study 2015;3(3):43-47

8. Nichols RL. Current Strategies for Prevention of Surgical Site Infection. Current Infect Dis Reports 2004; 6: 426434

9. Ali SA, Tahir SM, Shaikh NA, Pattern of Pathogens and their Sensitivity Isolated from Superficial Surgical Site Infections in a Tertiary Care Hospital. J Ayub Med Coll Aborttabad 2009;21(2):80-85

10. Wolcott RD, Gontcharova V, Suny Y, Zishchaknu A, Dowd SE. Bacterial diversity in Surgical Site Infections not just aerobic cocci anymore. $\mathrm{J}$ Wound Care 2009;18(8):317- 323

11. Saleem M, Subha TV, Balamurugan R, Kaviraj M, Gopal R. Bacterial Profile and Antimicrobial Susceptibility Pattern of Surgical Site Infections- A Retrospective Study. Indian J Applied Res 2015;10:204-206

12. Shamsuzzaman AK, Sirajee A, Rahaman AK, Miah AG, Hossain MA. Pattern of Aerobic Bacteria with their Susceptibility of Surgical Inpatients. Mymenshing Med J 2003;12(2):98-103
13. Ruhil K, Arora B, Adlakha H, Pseudomonas aeruginosa Isolation of Post operative Wound in a Referral Hospital in Haryana, India. J Infect Dis Antimicrobs Agents 2009;26:43-48

14. Sikka R, Jkamann D, Vashist MG, Chaudhary U, Deep A. Prevalence and Antibiotic Sensitivity Pattern of Bacteria Isolated from Nosocomial Infections in a Surgical Ward. Indian J Clin Prac 2012;20:10-15

15. Roel T, Devi Kh.S, Devi Ksh M, Sahoo B. Susceptibility Patter of Aerobic Bacterial Isolates from Wound Swab. Indian Med Gazette 2014;355-359

16. Bajaj A, Kukanur S, Kotigadde S, Meundi M. Gram Positive Cocci Causing Surgical Site Infection: Identification and Antibiotic Susceptibility Pattern. IOSR J Dental Med Sci (IOSR-JDMS) 2015;1(14):62-7.

17. Dessalegn L, Shimelis T, Tadesse E, Selassie SG. Areobic bacterial isolates from Post -operative Surgical Wound and their antimicrobial Susceptibility Pattern: A Hospital based Cross sectional Study. J Med Res 2014;3(2):18-23

18. Santos KRN, Fonseea LS, Neto GPB, Rilho PPG. Surgical Site Infection: Rates, Etiology and Resistance, Pattern to Antimicrobials among Strains Isolated at Riode Janeiro University Hospital. Originalia Infect 1997;25(4):217- 290

19. Pear SM. Patient Risk Factors and Best Practices for Infection Prevention and Managing Infection Control. 2007; 56-64

20. Diaz CDRV, Neeman J. Surgical Site Infection and Prevention Guide lines: A Primar for Certified Nurse Anesthetists. ANN J 2015;83(1):63-68 